International Journal of Advanced Chemistry, 2(2)(2014) $182-184$
International Journal of Advanced Chemistry
Journal home page: $\begin{gathered}\text { www.sciencepubco.com/index.php/IJAC } \\ \text { doi: } 10.14419 / \text { ijac.v2i2.3219 } \\ \text { Research Paper }\end{gathered}$

\title{
Tetrahydroanthracene Derivative: Anti-microbial Isolate from Acanthospermum hispidum DC
}

\author{
Olajide Olutayo Olawumi *, Oladosu Adebayo Ibrahim, Christianah Oluwaseun Fakunle \\ Natural Products/Medicinal Chemistry Research Unit, Department of Chemistry, University of Ibadan, Nigeria \\ *Corresponding author E-mail: olajidewumi@ rocketmail.com
}

\begin{abstract}
The leaves and stems of Acanthospermum hispidium were extracted with distilled ethanol using cold extraction and concentrated using a rotary evaporator at $37{ }^{\circ} \mathrm{C}$. The crude extract was partitioned successively using hexane, benzene and methanol. Fractions 19, 20 and 21 purified on Sephadex LH-20 gave a compound elucidated to be 1, 3, 6, 8-tetrahydroxyl-9-anthracene carbonaldehyde, using the state-ofart tools of spectrometry. The results of the antimicrobial test on the isolated compound show activity against P. mirabilis, B. subtilis, P. aeruginosa, C. albican, S. typhi and B. cereus at minimum inhibitory concentration (MIC) value of 100ppm.
\end{abstract}

Keywords: Acanthospermum hispidum, Anthracene Carbonaldehyde, Antimicrobial Test, Minimum Inhibitory Concentration.

\section{Introduction}

Ancanthospermum hispidum DC (Compositae) is a medicinal plant commonly known as 'ewe onitan meta' in western Nigeria. The plant is a bushy, annual of about $50 \mathrm{~cm}$ high, commonly found in a waste places or cultivated land. The cultivated specimens of Acanthospermum hispidium will germinate on a wide variety of soils, from sandy to clay. The transition from the flowering to the fruiting phase of this species is extremely rapid, demonstrating a metabolic priority of reproduction over the elaboration of chemical defences (Miranda, 1996). The leaves are used locally for the treatment of acute tuberculosis, cough, diarrhoea, dysentery, typhoid and pneumonia (Burkill, 1985). In Ghana, the leaves are used to cure kpiti (leprosy). In Congo the plant is used to treat stomach complaints, wounds and migraine. It is used throughout north eastern Brazil as a folk medicine for asthma (Evani' de, 2008).

Traces of alkaloid have been reported in the whole plant and in the leaves (Burkill, 1985). The ethanol extract of the leaves and flowering tops of Acanthospermum hispidum was showed to have varying degrees of activity against wide range of pathogenic bacteria but no activity was observed for the aqueous extract of the fresh plant material (Fleisher et al, 2003). The effects of administering Acanthospermum hispidum DC ethanolic leaf extract on patients of hepatitis were studied on acute hepatitis induced by carbon tetrachloride in rats (Edewor and Olajire, 2007). The effects were monitored by estimating the serum transaminases levels and the histopathological changes in the livers of experimental rats. The pre-treatment of the animals with Ancanthospermum hispidum DC leaf extract (0.3-2.0 g kg-1) significantly elevated the activities of the serum transaminases as well as the hepathotoxin-induced histopathological changes in the livers of experimental rats (Edewor and Olajire, 2007). Some of the compounds that have been isolated from the plant are acanthamolide, acanthoaustralide, germacratrienolide and it derivatives and loliolide (Antagera, 2000). In this paper, we report for the first time the anti-bacterial and cytotoxicity of the extracts obtained from the leaves and stems of Ancanthospermum hispidum DC and the newly identified compound, using the state-of-art-tools spectrometry.

\section{Materials and methods}

General: Column chromatography: silica-gel (merck, 60-200 mesh) Sephadex ${ }^{\text {TM }}$ LH-20 (GE health care Bio-science AB). IR spectra: FTIR Nicolet Avater 330, thermo-electron operation. ${ }^{1} \mathrm{H}$ and ${ }^{13} \mathrm{C}$ NMR mecury-200BB. Mass spectra: Fainnigan 4000 spectrometer (low resolution) krats 50 spectrometer (high resolution).

\subsection{Plant materials}

The leaves and stems of Acanthospermum hispidum DC were collected from the Department of Botany, University of Ibadan. The plant was identified by Mr Donatus Esimakhuai of the Herbarium section of the Department of Botany, University of Ibadan. It was later identified and authenticated by Dr. Ayodele of the same department, with Herbarium No UIH22301.

\subsection{Extraction and isolation}

Air dried leaves and stems $(800 \mathrm{~g})$ were milled into powder with the aid of an electrical grinder. Distilled ethanol (6 L) was added to the mixture of the plant in a stopper glass container. It was left for one week and then finally filtered. The ethanol extract obtained was concentrated at $37^{\circ} \mathrm{C}$ using rotary evaporator, at reduced pressure. It was then fractionated with n-hexane and methanol. The methanol extract was later macerated with benzene and were separately concentrated with rotary evaporator to give the refine-methanol and benzene extract respectively. The benzene extract was subjected to open column packed with silica gel (70220 mesh size) using a dry method. The column was eluted with a gradient of n-hexane/ethyl acetate. A total of 27 eluents were ob- 
tained. Phytochemical analysis was carried out on the chromatographic fractions. The eluents 19, 20 and 21, was seen to contained alkaloids. The fractions were combined together as fraction (A) based on their TLC pattern. The mixture was concentrated using rotary evaporator. Fraction (A) was loaded on the Sephadex LH-20. The column was eluted with methanol (100\%). Eluents were collected at $5 \mathrm{ml}$ rate. Two types of crystals were obtained which were purified using isopropyl alcohols separately. The two crystals were further subjected to $2 \mathrm{D}$ TLC. The best spot was sent for spectroscopic analysis.

\subsection{Anti-microbial screening}

The methanol and fraction (A) extracts were screened for antimicrobial activities against 5 standard strains of bacteria and a fungus: Staphylococcus typhi ATCC 2785, Bacillus subtilis ATTC 14579, Bacillus cereus ATTC 33923, Pseudomonas aeruginosa ATTC 27856, Proteus mirabilis ATTC 21784, Candida albican MTTC 227. The antimicrobial assay was performed according to standard method (Bauer et. al, 1996) zones of inhibition was measured with frequent ruler. Determination of MIC was conducted following Bauer Method. The results are presented in Table I.

\subsection{Brine shrimp lethality test (BST)}

The BST was performed according to standard protocol $(5,6)$ and $\mathrm{LC}_{50}$ values in $\mu \mathrm{g} / \mathrm{ml}$ were determined for partitioned fractions, pooled chromatographic fractions and isolated compound I. The results are presented in table II.

\section{Results and discussion}

The results of the phytochemical studies on the extracts of Ancanthospermum hispidum show the presence of alkaloids, phenolic compounds, resin, cardiac glycoside, saponins and tannins. This confirmed with what was reported by ( Odebiyi et. al,1978 and Sanon et.al, 2003).The results of the antimicrobial test on the methanol extracts and the isolated compound I are shown in Table I. The extract shows activity against P. mirabilis, B. subtilis, P. aeruginosa, C. albican, S. typhi and B. cereus at MIC of $100 \mathrm{ppm}$ The antimicrobial activities of the methanol extracts and compound I suggested their usefulness in the treatment of infectious diseases caused by the tested microbes. BST results of the methanol extract gave $\mathrm{LC}_{50}>1000$. This value indicated that the methanol extract is non-toxic. However $\mathrm{LC}_{50}$ result on compound I was not converged after several attempts. Compound I (1, 3, 6, 8tetrahhydroxy-9-anthracene carbaldehyde) was obtained as brown crystals. On purification with isopropyl alcohol, the crystals turned dirty white. The IR spectrum showed the characteristics signals of $-\mathrm{OH}\left(3471 \mathrm{~cm}^{-1}\right)$, conjugated carbonyl carbon $\left(1658 \mathrm{~cm}^{-1}\right), \mathrm{C}=\mathrm{C}$ $\left(1444 \mathrm{~cm}^{-1}\right), \mathrm{C}-\mathrm{O}$ stretching vibration $(1210 \mathrm{~cm}-1)$ and fingertip region of aromatic benzene skeleton. The $\mathrm{C}-\mathrm{H}$ stretching vibration at $2900 \mathrm{~cm}-1$, is not very pronounced due to lack of aliphatic moiety. The UV spectra data of compound I was characteristics of the anthracene chromophore and the sodium acetate addition caused a bathochromic shift, indicating the presence of hydroxyl group; the consecutive addition of $\mathrm{H}_{3} \mathrm{BO}_{3}$ did not modify the UV spectrum, suggesting the absence of the ortho hydroxyls. The molecular formula was determined as $\mathrm{C}_{15} \mathrm{H}_{10} \mathrm{O}_{5}$ on the basis of HREMS (m/z 270.115 cal. 270.314). The standard ${ }^{13} \mathrm{C}$ NMR spectrum as well as polarization transfer (DEPT) experiment of compound I depicted fifteen carbon atoms. The ${ }^{13} \mathrm{C}$ NMR (DEPT) showed resonance for nine quaternary carbons and six methines giving an attached proton formula of $\mathrm{C}_{15} \mathrm{H}_{6}$. This molecular formula possesses a double bond equivalent of eleven, which was consistent with the exact mass measurements. The clustering of signals between $\delta 7.05$ and 7.99 in ${ }^{1} \mathrm{HNMR}$ spectrum of compound 1 is a characteristic of phenolic or aromatic moiety. The presence of signal at $\delta 10.5$ which crossed peak with $\delta \mathrm{C}$ at 171.1 is an indication of aldehydes functional group. Absent of aliphatic entity was supported due to no signal up field in the ${ }^{1} \mathrm{HMNR}$ of compound 1 . The ${ }^{1} \mathrm{HMNR}$ spectrum in the aromatic region showed five protons in three different environments. The integral pattern in ${ }^{1} \mathrm{HMNR}$ depicted $2: 2: 1: 1$. The signals downfield which are not directly attached to any carbon in HSQC experiment also corroborated the presence and attachment of heteroatoms like oxygen. The coupling constant displayed by the ${ }^{1} \mathrm{HMNR}$ spectrum in all coupled protons is within $1.4 \mathrm{~Hz}$ suggesting Meta coupling arrangement. The connectivity within the molecule was shown by ${ }^{1} \mathrm{H}^{-1} \mathrm{H}$ cosy and $\mathrm{HMBC}$ experiments. The ${ }^{1} \mathrm{HMNR}$ spectrum showed the presence of five aromatics protons at $\delta 7.58(2 \mathrm{H}, \mathrm{d}, \mathrm{J}=1.4 \mathrm{~Hz}), \delta 7.99(1 \mathrm{H}, \mathrm{s})$ and $\delta$ $7.05(2 \mathrm{H}, \mathrm{d}, \mathrm{J}=1.4 \mathrm{~Hz})$. The proton at $\delta 9.98$ suggested the presence of an aldehydes moiety. The connectivity between the proton of the aldehydes and that of the benzene moiety was done through ${ }^{1} \mathrm{H}-{ }^{1} \mathrm{H}$ cosy cross- peaks. The broad nature of the $\mathrm{OH}$ in IR spectrum also corroborates the presence of aldehydes moiety closer to $\mathrm{OH}$ entity. A ${ }^{1} \mathrm{H}_{-}{ }^{13} \mathrm{C} 2 \mathrm{D}$ NMR shift correlated measurement (HMBC) showed long range coupling between $\mathrm{H}-17$ and $\mathrm{H}-21 / \mathrm{H}-$ 10 ; $\mathrm{H}-12$ and $\mathrm{H}-20$ which is consistent with and independently confirming the structure of compound I. Based on the spectra data, the compound is trivially named 1, 3, 6, 8-tetrahydroxy-9anthracene carbaldehyde in figure I.

Table 1: Antimicrobial Activity of Methanol Extract

\begin{tabular}{lll}
\hline Micro- organism & \multicolumn{2}{l}{ Zone of inhibition $(\mathrm{mm})$} \\
\hline & Methanol & Isolated compound \\
P.aeruginosa & 12.7 & 15.0 \\
P.mirabilis & 12.0 & 13.0 \\
B.subtilis & 12.3 & 12.0 \\
C.albican & 9.0 & 14.0 \\
S.typhi & 11.0 & 13.3 \\
B.cereus & 9.7 & 14.3 \\
\hline
\end{tabular}

Table 2: ${ }^{1} \mathrm{HMNR}$ and ${ }^{13} \mathrm{C}$ NMR of Compound I

\begin{tabular}{|c|c|c|c|c|c|}
\hline $\mathrm{s} / \mathrm{n}$ & $\delta \mathrm{H}$ & M & I.f & $\Delta \mathrm{c}$ & HMBC(H/C) \\
\hline 1. & - & & & $162.4(\mathrm{~s})$ & \\
\hline 2. & 7.05 & $\mathrm{D}$ & $1 \mathrm{H}$ & $99.3(\mathrm{~d})$ & $3 / 6,4 / 5,9 a / 8 a, 1 / 8$ \\
\hline 3. & & & & $149.9(\mathrm{~s})$ & \\
\hline 4. & 7.58 & D & $1 \mathrm{H}$ & $115.6(d)$ & $4 a / 10 a, 10,9 a / 8 a$ \\
\hline $4 a$. & & & & $119.8(\mathrm{~s})$ & \\
\hline 5. & 7.58 & $\mathrm{D}$ & $1 \mathrm{H}$ & $115.6(d)$ & $4 a / 10 a, 10,9 a / 8 a$ \\
\hline 6. & & & & $149.9(\mathrm{~s})$ & \\
\hline 7. & 7.05 & $\mathrm{D}$ & $1 \mathrm{H}$ & $99.3(\mathrm{~d})$ & $3 / 6,4 / 5,9 a / 8 a, 1 / 8$ \\
\hline 8. & - & & & $162.4(\mathrm{~s})$ & \\
\hline $8 a$. & & & & $97.1(\mathrm{~s})$ & \\
\hline 9. & & & & $118.6(\mathrm{~s})$ & \\
\hline 9a. & & & & $97.1(\mathrm{~s})$ & \\
\hline 10. & 7.99 & $\mathrm{~S}$ & $1 \mathrm{H}$ & $131.2(\mathrm{~d})$ & $4 a, 8 a, 9 a, 10 a$ \\
\hline $10 \mathrm{a}$. & 9.98 & Bs & $1 \mathrm{H}$ & $119.8(\mathrm{~s})$ & $9,9 \mathrm{a}$ \\
\hline 11. & & & & $171.1(\mathrm{~d})$ & \\
\hline
\end{tabular}

UV $\lambda \max \left(\mathrm{CHCl}_{3}\right) 251 \mathrm{~nm}$;

IR (Nujor): $3538(\mathrm{OH}) ; 1051(\mathrm{C}-\mathrm{O}) ; 1600(\mathrm{C}=\mathrm{C})$ and $2958(\mathrm{CH}$ srt)

EIMS (low and high resolution): m/z $398(80 \%)-\mathrm{H}_{2} \mathrm{O}, 317 ; 300$; 224

CIMS m/e 190.2, 189.2, 188.1, 121.3, 69, 42.9<smiles>O=Cc1c2c(O)cc(O)cc2cc2cc(O)cc(O)c12</smiles>

Fig. 1: Structure of Phenanthrenol

${ }^{1} \mathrm{H}$ NMR $\left(400 \mathrm{MHz}, \mathrm{CHCl}_{3}\right): \delta 1.10(3 \mathrm{H}, \mathrm{t}, \mathrm{H}-30) ; \delta 2.65(1 \mathrm{H}$, bm, H-6); $\delta 6.53(1 \mathrm{H}, \mathrm{d}, \mathrm{H}-17) ; \delta 4.10(2 \mathrm{H}, \mathrm{m}, \mathrm{H}-18) ; \delta 5.00(1 \mathrm{H}$, $\mathrm{m}, \mathrm{H}-19) ; \delta 5.01(1 \mathrm{H}, \mathrm{m}, \mathrm{H}-22) ; \delta 5.34(1 \mathrm{H}, \mathrm{M}, \mathrm{H}-23)$

${ }^{13} \mathrm{C}$ NMR (100 MHz, $\mathrm{CHCl}_{3}$ ): see Table I 


\section{Conclusion}

The structure of the compound gotten conforms to that which has been reported before and this is only a derivative of the compound found in Acanthospermum hispidum DC. The extracts of the plant has also been shown to have antimicrobial properties.

\section{Acknowledgement}

IAO is grateful to University of Ibadan, Nigeria, for the staff development given to him.

\section{References}

[1] Antagera E, Bardon A, Catalain CA; J.Nat. Product, 2000, 63 (10), Pages 1323-1328. http://dx.doi.org/10.1021/np9905057.

[2] Bauer AN, Kirby,WM, Sherris,JC, \& Turck, M..Amer. J. Clinical path., 1996 45:493-496.

[3] Burkill HM The Useful Plants of West Tropical Africa [Edition 2] Royal Botanical Gardens KEW.1985 Vol 1, Pages 641-643.

[4] Edewor,A, Olajire, AA and Olaniyan EB,. Research journal of Medical Sciences (1).2007, Pages 39-41.

[5] Evani'de L, Aranjo,Karina P .Brazilian J.of Pharmacognosy,2008, 18:777-784.

[6] Fleisher TE., Ameade, EP and Sawer IK, Antimicrobial Activity of the Leaves and Flowering tops of Acanthospermum Hispidum, 2003, Pages 74-76.

[7] Miranda LFP. Instituto de Biologia da Universidade Federal da Bahia, 1996, Page 78

[8] Odebiyi OO, Sofowora EA. Lloydia, 1978, 41: 234-246.

[9] Sanon, S; Azas, N; Gasquet, M; Ollivier, V.Parasitology Research, 2003, Vol.90 (4): Pp 314-317. http://dx.doi.org/10.1007/s00436-003 0859-9.

[10]Sofowora EA, Research Trends in Medicinal plants in Africa, Spectrum Book Ltd., Ibadan, 1982, Pp. 80-82. 